\title{
PERSPECTIVAS DE LOS MOVIMIENTOS SOCIALES Y LA PROBLEMÁTICA DEL ESTADO: LAS FORMAS DEL CAMBIO SOCIO-POLÍTICO A FINES DEL SIGLO XX
}

\section{PERSPECTIVES OF SOCIAL MOVEMENTS AND THE PROBLEMATICS OF STATE: FORMS OF SOCIO-POLITICAL CHANGE AT THE END OF THE TWENTIETH CENTURY}

\section{Esteban Iglesias*}

\begin{abstract}
RESUMEN
El propósito de este artículo es analizar el modo en que dos perspectivas de la acción colectiva abordan el problema del Estado y como consecuencia de ello, la forma en que se concibe la transformación social a fines del siglo xx en sociedades atravesadas por el problema de la igualdad. El argumento que se desarrolla es que la perspectiva identitaria ha sobredimensionado el lugar de los movimientos sociales asignándoles el papel de "democratizadores" de la sociedad, mientras que el enfoque de la movilización de recursos ha replicado esto con la esfera estatal. Lo cierto es que entre ambas concepciones queda un espacio teórico que no ha sido explorado exhaustivamente en el marco de la acción colectiva, el de la mutua incidencia entre Estado y movimientos sociales. Esto abre nuevas posibilidades para continuar debatiendo acerca de los caminos hacia sociedades más igualitarias.
\end{abstract}

PALABRAS CLAVE: MOVIMIENTOS SOCIALES * ACCIÓN COLECTIVA * ESTADO * CAMBIO SOCIAL * IGUALDAD DE DERECHOS

\section{ABSTRACT}

The aim of this article is to analize the way in which two perspectives regarding collective action approach the problem of the State and as consequence of it, the way in which social transformation is conceived at the end of the 20th century in societies crossed by the problem of the equality. The argument developed is that the identity perspective has oversized the place of the social movements assigning them the role of democratizers" of society, the approach of resources mobilization has replicated this with the state sphere. What is certain is that between both conceptions there is a theoretical space that has not been explored exhaustively in the frame of the collective action, such space is that of the mutual incidence between State and social movements. This opens new possibilities to continue debating about of the pathways towards more equitable societies.

KEYWORDS: SOCIAL MOVEMENTS * COLLECTIVE ACTION * STATE * SOCIAL CHANGE * EQUAL RIGHTS

Facultad de Ciencias Políticas y Relaciones Internacionales de la Universidad Nacional de Rosario, Argentina. estebantatiglesias@yahoo.com.ar 


\section{INTRODUCCIÓN ${ }^{1}$}

Los debates y polémicas acerca de las modalidades en que las sociedades del siglo xx pueden ser más igualitarias se tornaron recurrentes a partir de la creación legal y la ampliación de electorados desde mediados de siglo xix. En efecto, los procesos de democratización colocaron al principio de la igualdad como problema relevante en la sociedad. Estos debates han involucrado a diferentes tradiciones teóricas, desde el marxismo hasta el liberalismo, $y$ han impactado fuertemente en la práctica política, así como también las experiencias políticas ocurridas constituyeron un formidable nutriente para reformular las teorías. Una muestra cabal de ello fueron, desde la izquierda, las discusiones mantenidas entre Bernstein, Kautsky, Luxemburgo y Lenin en el marco de la Segunda Internacional Obrera, $y$ al interior del liberalismo, la propuesta igualitarista de Rawls.

Este trabajo se concentra en la problemática de la acción colectiva, situada en el último tercio del siglo xx, momento en que la crisis del Estado de Bienestar se revela nítidamente. Su propósito radica en describir el modo en que concibieron los principales referentes teóricos de las perspectivas de la acción colectiva, la cuestión del Estado y las diversas orientaciones que se desprenden para el cambio político.

El argumento que se desarrolla es que las posiciones divergentes en torno a las modalidades que asume la transformación de la sociedad, se explican por el papel sobredimensionado que se le asigna a los movimientos sociales por parte de la "perspectiva identitaria" y por la centralidad adjudicada a la esfera estatal por el enfoque de la movilización de recursos.

Si este argumento resulta ser válido, en este trabajo se advierte que en la problemática de la acción colectiva existe un espacio teórico a explorar que explique de forma sistemática el conjunto de interacciones e influencias mutuas que se establecen entre la esfera estatal y la acción de los movimientos sociales. Este equilibrio dotaría de mayor sensibilidad a las herramientas conceptuales de la acción colectiva

1 Agradezco las sugerencias de los evaluadores anónimos, los cuales han permitido mejorar el artículo. con el objeto de atender la diversidad empírica $y$ fundamentalmente, contribuir a los debates sobre la igualdad en sociedades democráticas.

Cabe destacar que esta problemática cobra nueva importancia una vez institucionalizado el movimiento obrero (Eley 2003), luego de la Segunda Guerra Mundial, momento en que se definen los contornos del Estado de Bienestar (Offe 1990). Sin embargo, el consenso político de posguerra no estuvo exento de vicisitudes. En efecto, esta situación de relativa estabilidad estuvo caracterizada por diversas transformaciones en el plano político. Por un lado, la profunda modificación de las organizaciones partidarias clasistas que, de acuerdo con Kirchheimer (1980), comenzaron a asumir características de "atrapa todo" o de agencias electorales. Por otro lado, los cambios en la dimensión de la representación política cuya nota distintiva consistió en la "personalización de las opciones electorales" y en la "volatilidad del voto" (Manin 1998). Esta situación no era muy alentadora, más bien, abonaba un clima de pesimismo para los cientistas sociales que pregonaban por sociedades más igualitarias. Asimismo, algunos pensaron que las fuentes del conflicto social se habían agotado, así como también las posibilidades del cambio político. La emergencia y consolidación de "nuevos" movimientos sociales brindó a los teóricos un nuevo panorama para el análisis, ya que estos colocaron en la agenda política nuevos temas $y$ peticiones, ampliando el principal clivaje que dividía a la sociedad y que giraba en torno de la distribución de la riqueza.

Entonces, institucionalizado el movimiento obrero, el protagonismo de la protesta social estuvo asumido por distintos movimientos sociales, siendo los más relevantes el movimiento gay, el ecologismo, el feminismo, el pacifismo, pro-derechos civi$\mathrm{les}^{2}$, entre otros. Asimismo, el movimiento obrero no perdió importancia, lo notorio fue que el conflicto que se expresaba comenzó a canalizarse institucionalmente. Los nuevos

2 Para un análisis de la emergencia de los "nuevos" movimientos sociales puede consultarse: Cohen y Arato (2000), Pérez Ledesma (1994), Rasche (1994), Revilla Blanco (1994) y Tarrés (1992). 
sujetos de la protesta eran una "clase media" que no consignaba problemas económicos apremiantes. La emergencia de este novedoso protagonista orientó a los cientistas sociales a preguntarse ¿quién?, ¿de qué modo?, ¿cuáles eran las razones por las que se protestaba? y fundamentalmente, ¿qué caminos se podían transitar para la transformación política de la sociedad? En este marco de problemas surgieron dos tipos de respuestas teóricas: la perspectiva de los movimientos sociales y el enfoque de la movilización de recursos.

\section{LA PERSPECTIVA DE LOS MOVIMIENTOS SOCIALES}

En lo que se refiere a la "perspectiva identitaria" o "perspectiva europea" de los movimientos sociales, entre los principales referentes teóricos se encuentran a Touraine, Offe, Melucci, Habermas, y Cohen y Arato.

Para estos autores, la dimensión identitaria constituye el punto de partida de su reflexión sobre la acción colectiva y uno de sus aspectos distintivos. Se entiende que la constitución de una identidad social se produce en el marco de un conflicto en la sociedad. Desde las teorizaciones de Touraine de mediados de los 70 a las de Cohen y Arato de mediados de los 90 del siglo xx, se puede reconocer una relevante inflexión teórica: de la diferenciación entre movimiento social, Estado y partidos políticos se pasa a una reflexión sistemática sobre la sociedad civil, en tanto terreno privilegiado para la transformación política.

Esta perspectiva evalúa que las iniciativas estatales colonizan, burocratizan o cooptan la organización política desarrollada en la sociedad civil, principalmente, la referida a la actuación política de los movimientos sociales. Por un lado, se descarta la arena estatal como lugar de disputa política. Por otro lado, en términos de reflexión teórica, el fiel de la balanza queda inclinado hacia la sociedad. Esta mirada "societalista" de la acción colectiva no termina de explorar teóricamente las posibilidades de transformación política que ofrecería un análisis más equilibrado en lo que respecta a las interacciones entre Estado $y$ movimientos sociales.

\section{LAS CONNOTACIONES CONCEPTUALES DEL MOVIMIENTO SOCIAL}

Pionero en la temática y preocupado por las modalidades que asume la transformación social, Touraine (1995) considera que el concepto de "movimiento social" es equivalente al de "clase social". Efectivamente, tras el descrédito experimentado por la "política centrada en la clase" (Eley 2003) que había orientado la acción política del socialismo con el objeto de transformar o sustituir al capitalismo, los movimientos sociales aparecen como un poderoso relevo conceptual a partir del cual se pueden formular diversos caminos del cambio político en las sociedades del siglo xx.

El status teórico otorgado al "movimiento social" le implicó a Touraine considerar que no todo tipo de acción colectiva debe identificarse con este. Así, distinguió entre diferentes niveles de acción colectiva, más bien denominadas conductas colectivas. Así se reconocieron:

1. Crisis organizativas: se producen cuando los miembros de una organización presentan reivindicaciones a quienes deten$\tan$ la autoridad. Lo que se pone en tela de juicio es quién detenta la jefatura de la organización.

2. Tensiones institucionales: remiten a los actores sociales y a la influencia de los mismos sobre las decisiones que serán obligatorias a una colectividad. El ejemplo paradigmático es el del accionar sindical, es decir, un tipo de organización que es reconocida por el Estado y que intenta influir mediante la presión política sobre las iniciativas estatales.

3. Movimiento social: es el accionar de la clase social y su rango de acción es el de la historicidad. El accionar del movimiento social se revela cuando la organización política de la sociedad "produce" un tipo de accionar que coloca en tela de juicio las orientaciones políticas de la sociedad en un período histórico dado (Touraine 1995, 240-247).

En la definición de movimiento social intervienen tres principios: el de identidad, el 
de oposición y el de totalidad. Para Touraine (1995), cabe advertir, que estos se encuentran en plena interacción y que su delimitación y diferenciación es sencillamente analítica. Con esta se destaca que la definición del actor por sí mismo (momento identitario) se realiza en el marco de un conflicto a partir del reconocimiento de un adversario (momento de la oposición) y finalmente, se aproxima a la elaboración de nuevas orientaciones, un modelo cultural, que colocan en tela de juicio el modo en que la sociedad se organiza políticamente (momento de la totalidad).

Entonces, ¿cómo aparece la problemática del Estado? El principio de "totalidad" y por lo tanto, el criterio decisivo para la constitución de un movimiento social es el que orienta hacia la arena estatal y a comprender el conjunto de interacciones con las iniciativas que emanan de este.

Para Touraine (1995), la acción del movimiento social ni la acción política puede estar exclusivamente orientada hacia el Estado. En términos conceptuales como de práctica política, el campo de acción del movimiento social excede el de la arena estatal, situándose así en el campo de la historicidad. Ciertamente, las similitudes con el razonamiento gramsciano son notables. Para Gramcsi, el Estado no es una fortaleza a la que hay que asaltar sino, más bien, la última de las trincheras. De acuerdo con esto $y$ en el marco del pensamiento de Touraine, un cambio profundo se registra cuando no solo se modifican las instituciones sino cuando el mismo involucra a la organización política de la sociedad y sus modelos culturales. Activar el principio de la "totalidad" en términos de accionar político implica que "... el Estado no puede ser el único medio del que dispone el movimiento social para apuntar a la totalidad" (Touraine 1995, 291).

La persistencia de un movimiento social depende de que se encuentre activo el principio de "totalidad". Sin embargo, este se disputa desde diferentes lugares. Así, la pérdida del radicalismo inicial puede ser generada debido a la intervención de la clase dominante y a las iniciativas estatales en la organización social. A su vez, desde el mismo movimiento social se puede reclamar la incorporación al sistema institucional. Ambas situaciones interfieren en el desarrollo del principio de "totalidad", pero no necesariamente implican la desaparición del movimiento social.

\section{NUEVOS MOVIMIENTOS Y SOCIEDAD CIVIL: EL LUGAR DEL CAMBIO POLÍTICO}

Al encontrarse el Estado de Bienestar afianzado en Europa, Offe (1992) critica a las organizaciones partidarias predominantes y avisa un declive del sistema que forjaron. $\mathrm{Su}$ crisis respondía a que estos partidos deformaban los intereses de las identidades colectivas que representaban y la situación se distinguía por la emergencia de nuevos temas en el espacio público que no eran capaces de canalizar. Este contexto abre un nuevo espacio para pensar teóricamente $y$ concebir nuevas posibilidades para el cambio político. Para Offe (citado en Colom 1992), los "nuevos movimientos sociales" constituyen un nuevo paradigma político que "prolongaría el eje trazado históricamente por las corrientes liberal y socialista" (Colom 1992,17) en el siglo xvIII y xIx, respectivamente.

Los movimientos sociales expresaron para el autor un nuevo paradigma político, ya que implicaron una modificación profunda en los patrones del comportamiento político que signaba a la "sociedad del trabajo". En este sentido, se registraron transformaciones en los "temas", "valores", "modos de acción política" y en la "organización" que se dieron, lo cual orienta a pensar en un nuevo "paradigma" de la política.

El énfasis en los valores no es casual. En la perspectiva identitaria se remarca que el ecologismo, el pacifismo, el feminismo, los derechos humanos, entre otros, expresaron una nueva gramática política que impactó en la dimensión subjetiva y en el terreno de la socialización de los hombres, no así en la de la distribución de la riqueza o en el de la seguridad. Frente a las posibilidades de manipulación, control o burocratización a la que se encuentran expuestas las organizaciones de masas (partidos y sindicatos), los movimientos sociales mencionados, mediante su accionar político, priorizan la constitución de una "identidad colectiva”. Para ello, carecen por definición, de 
los mecanismos políticos de la "negociación". Entonces, sin nada para ofrecer, los movimientos se erigen como instancias de "visibilidad" de un conflicto, antes que de representación de intereses en la arena pública. Además, hay que destacar que los reclamos de los movimientos sociales, a pesar de ser impulsados por sectores de clase media, no expresan intereses de clase $y$ en ese sentido, tienen un "carácter marcadamente universalista", involucrando así a toda la población o comunidad (Offe 1992, 234); de ahí el "sentido democrático" que distingue a los nuevos movimientos sociales. Finalmente, el nuevo paradigma que se caracteriza encuentra en el terreno de la "sociedad civil", el lugar propicio para desafiar "tanto a las prácticas e instituciones privadas como a las correspondientes de la política institucional" (Offe 1992, 230).

Consolidados los nuevos movimientos, la preocupación por su institucionalización se incrementa. A raíz de esto, Offe (1992) propone un "modelo experimental" para la auto-transformación institucional de los nuevos movimientos, en el que se considera la necesidad de la constitución de un "colectivo" y a su vez, que no se agoten sus energías transformadoras. Las etapas que plantea son: 1 . de la constitución identitaria se deriva; 2 . la formación organizativa, de la cual emergen las exigencias de; 3 . la institucionalización, lo que expone al movimiento a; 4. regenerar la identidad constituida mediante un "autoaprendizaje institucional" basado en la "influencia institucional" lo que permite evadir para el autor, los fundamentalismos que emergen con frecuencia en la acción política (Offe 1992, 277 y 292). El nacimiento e institucionalización del Partido Verde alemán para el autor constituyó un claro ejemplo.

Lo cierto es que en esta perspectiva teórica tomó consistencia una idea: la acción política de los movimientos sociales se localiza en la sociedad civil, lugar desde el que se irradia e influye sobre la esfera estatal con el propósito de dotar de sentido y legitimidad, las decisiones vinculantes que se elaboran en el parlamento. Melucci (1999) expresa que la emergencia de movimientos sociales en la sociedad civil y su accionar en la esfera pública es revelador de nuevos códigos culturales que confrontan con el aparato político.

Los problemas teóricos que se suscitaron fueron abordados por Cohen y Arato (2000), quienes elaboraron una teoría sistemática de la sociedad civil articulada con una teoría de la democracia. Las lógicas de acción política asignadas a los movimientos en el terreno de la sociedad civil ahora asumen un carácter sistemático.

Sin embargo, no hay que dejar de señalar que las lógicas que imperan en las iniciativas estatales $y$ en la sociedad civil fueron previamente planteadas por Habermas (1989). Con la modernidad, el Estado ha "colonizado" el mundo de la vida, modificando el modo en que construye la pertenencia a una comunidad política: el ciudadano en la esfera pública se ha convertido en un "cliente" y en la esfera privada en un "consumidor". Asimismo, el Estado de Bienestar, mediante la institucionalización del conflicto entre el "capital" y el "trabajo", ha desencadenado nuevos potenciales de protesta. Para Habermas “...los nuevos conflictos se desencadenan no en torno a problemas de distribución, sino en torno a cuestiones relativas a la gramática de las formas de vida (1989, 556). Esta gramática se expresa en conflictos relativos a los derechos humanos, la calidad de vida, la igualdad de derechos y la autorrealización individual.

Los conceptos de esfera pública para Habermas (1998) y de sociedad civil para Cohen y Arato (2000) presentan rasgos distintivos del Estado y de las organizaciones de masas en lo que respecta a las formas de acción política. Para Cohen y Arato en la sociedad política y en la sociedad económica, los actores participan de forma directa en el poder del Estado y en el de la producción económica respectivamente, a los cuales procuran "controlar" y "manejar". Sin embargo, los diversos elementos que integran la sociedad civil no están relacionados con la conquista del poder sino, más bien, “...con la generación de influencia mediante la actividad de las asociaciones democráticas y la discusión no restringida en la esfera pública cultural. Tal papel político es inevitablemente difuso e ineficaz" (Cohen y Arato 2000, 9). De acuerdo con 
lo anterior, la definición operativa de sociedad civil remite a "... una esfera de interacción social entre la economía y el Estado, compuesta ante todo de la esfera íntima (en especial la familia), la esfera de las asociaciones (en especial las asociaciones voluntarias), los movimientos sociales y las formas de comunicación pública" (Cohen y Arato 2000, 3).

A diferencia de las reflexiones iniciales, estos autores no consideran que los movimientos sociales deben reemplazar, por ejemplo a los partidos socialistas —en referencia a Offe- así como tampoco le asignan el peso conceptual que tenía el de "clase social" —en referencia a Touraine. En un contexto de crisis del marxismo y del pluralismo, en tanto formas de explicar el funcionamiento político de las sociedades, Cohen y Arato consideran que la transformación social no implica eliminar el capitalismo o la burocracia, o reemplazar "sujetos" (clase obrera) de cambio político. Más bien, entienden que la sociedad civil es el principal terreno de lucha política y el ámbito adecuado para que las sociedades democráticas sean más igualitarias. En este sentido, los movimientos sociales constituyen el "costado ligero" de la definición operativa de sociedad civil y son los protagonistas, al igual que los desobedientes civiles, de una posible transformación política.

En definitiva, descartado el Estado, en tanto lugar donde se batalla por transformar la sociedad y a su vez, reubicado este en una esfera más de interacción humana, para estos autores la política se ha replegado sobre la sociedad civil. En efecto, se piensa que el accionar político de los movimientos sociales (reclamos universales, no clasistas) y las asociaciones en general, constituyen un arma poderosa para influir sobre la esfera política o el poder administrativo. Este rasgo teórico es decisivo: el poder comunicativo construido socialmente en la sociedad civil debe dirigirse hacia el poder administrativo, único modo en que decisiones vinculantes se convierten en legítimas.

\section{ENFOQUE DE LA MOVILIZACIÓN DE RECURSOS}

Conocido como la perspectiva "estadounidense", este enfoque encuentra en Olson,
McCarthy, McAdam, Zald, Tarrow, Tilly, entre otros, a sus principales referentes teóricos.

Entre los principales aportes se ha consignado que la acción colectiva constituye una regularidad en el accionar político y que esta no puede explicarse por las desigualdades socio-económicas. En sociedades en las que las diferencias sociales se morigeraron, existen "recursos" como el prestigio, el poder, el dinero, la cultura y la organización, a los que pueden apelar los grupos sociales para iniciar una acción colectiva.

Ahora bien, el interrogante que intenta atender esta perspectiva consiste en ¿cuándo, de qué modo y qué impacto produce la acción colectiva? Responder esta pregunta requiere desarrollar los conceptos de "organización", "oportunidades políticas" y procesos tendientes a democratizar el Estado y la sociedad.

Esta perspectiva responde los interrogantes formulados sobre la acción colectiva, otorgándole centralidad al Estado y a las características que históricamente este asume. Con ello, no se puede mensurar en qué medida el papel de los movimientos sociales contribuyó a que las sociedades sean más igualitarias y asimismo, cuál fue el impacto de su accionar político en el marco estatal. En términos teóricos, el fiel de la balanza se inclina sobre la esfera estatal y queda pendiente una explicación que logre mayor equilibrio en los puntos de contacto entre movimientos sociales e iniciativas estatales.

\section{LA ORGANIZACIÓN COMO ORIGEN Y DESTINO}

La cuestión de la "organización" constituye el punto de partida de esta perspectiva de la acción colectiva. En efecto, la presencia de una "organización" o de "organizaciones" posibilita y explica la duración y los efectos que produce la acción colectiva en la sociedad.

Olson (1992) en el estudio sobre lo que considera las organizaciones más importantes de un país (sindicatos, organizaciones rurales y colegios profesionales) planteó la problemática de los "costos" y "beneficios" a los que se encuentra expuesta la acción colectiva. Así, registra la existencia de costos de "organización", de "comunicación" y principalmente de "negociación". Para este autor, la acción colectiva se 
enfrenta al siguiente problema: si el beneficio para los implicados en una acción colectiva no se encuentra asegurado, cómo se solventan el conjunto de costos mencionados (Olson 1992). De esta manera, se interpreta que la percepción de incentivos selectivos por parte de miembros de la organización es lo que posibilita y sobre todo, garantiza la acción colectiva.

Ahora bien, serán teorizaciones posteriores a las de Olson las que expliquen no solo lo que posibilita la acción colectiva, sino además, la duración y sus efectos en la sociedad. Así, el término "estructuras de movilización" alude a canales colectivos, formales e informales de los que se sirve gente común y corriente para implicarse en una acción colectiva. De acuerdo con McCarthy (1999), se alude específicamente a "repertorios tácticos", a "formas organizativas concretas" y a "repertorios modulares" de los movimientos sociales en los que intervienen unidades familiares, redes de amigos, asociaciones voluntarias, centros de trabajo y elementos de la propia estructura del Estado.

Para este enfoque, los recursos sociales en general $y$ las organizaciones en particular, constituyen un medio a partir del cual los movimientos sociales extraen su fuerza para transformar la sociedad. Ahora bien, queda pendiente explicar ¿en qué momento se utilizan todos estos recursos para activar la acción colectiva?

\section{OPORTUNIDADES POLÍTICAS Y REPERTORIOS DE CONTENCIÓN}

Para este enfoque, el potencial de movilización política no se explica por las estructuras sociales subyacentes, más bien, existen momentos en que la acción colectiva cobra forma. El concepto de "estructura de oportunidades políticas"3 cristaliza el momento netamente político que permite explicar cómo surge, cuánto dura y qué forma asume la acción colectiva. En este sentido, las "oportunidades políticas" para Tarrow (2004) permiten observar el modo en

$3 \quad$ Para una revisión de la literatura, en especial acerca de los acuerdos y desacuerdos en la conceptualización y operacionalización de este concepto se puede consultar Doug McAdam (1999). que los elementos de la acción colectiva se encuentran determinados “... por el flujo y reflujo de la lucha política".

Las dimensiones del concepto "estructura de oportunidades políticas” son: “...1) la apertura del acceso a la participación de nuevos actores; 2) las pruebas de nuevas alianzas políticas en el seno del gobierno; 3 ) la aparición de aliados influyentes; 4) la aparición de divisiones entre los dirigentes; y 5) una disminución en la capacidad o la voluntad del Estado de reprimir la disidencia" (Tarrow 2004, 116).

La pretensión analítica de las oportunidades políticas para Tarrow radica en que se entienda a partir de un "estatalismo dinámico", es decir, un tipo de explicación conceptual, sujeta a variaciones históricas, que enfatice en las interacciones $y$ la mutua influencia entre Estado $y$ movimientos sociales.

La idea de "estatalismo dinámico" atiende, al menos, tres cuestiones. Por un lado, plantea que las relaciones de la acción colectiva $y$ los movimientos sociales con el Estado no implican procesos de cooptación o burocratización como lo considera la perspectiva de los movimientos sociales. Por otro lado, matiza los abordajes que, desde el enfoque de la movilización de recursos, hacían énfasis en el grado de apertura o de cierre del Estado o el régimen político para explicar por qué gente común ponía en riesgo su vida lanzándose a una acción colectiva (Tarrow 1997). Finalmente, las relaciones de los movimientos sociales con el Estado permiten pensar de acuerdo con McAdam (1999), McCarthy (1999) y Zald (1999), el modo en que estos intervienen en procesos de democratización, teniendo presente que los movimientos sociales extraen su fuerza de cambio social de las organizaciones que generan.

El concepto "estructura de oportunidades políticas" ha recibido innumerables críticas. Tarrow ha saldado alguna de ellas con su idea de "estatalismo dinámico", sobre todo, las que se dirigían a que el enfoque de la movilización de recursos constituía una mirada "desde arriba" e "institucionalista" de la acción colectiva. Sin embargo, fueron los estudios provenientes de la "sociología histórica" los que ofrecieron otro tipo de mirada analítica. Tilly (2000) con 
su idea de "repertorios de contención" explica cómo se modificó el accionar político de la sociedad, es decir, la acción colectiva en la larga duración. Claro está que para Tilly, las sociedades no poseen infinitas formas de protestar. Precisamente, la idea de repertorio apunta a considerar que las formas son más bien limitadas y que estas se imponen con el tiempo gracias a su efectividad. En efecto el concepto de "repertorio" logra capturar libretos de la acción colectiva producto de la interacción de: 1) cambios producidos por aprendizaje, innovación y negociación en el curso de la propia acción colectiva; 2) transformaciones en el entorno institucional y 3) las interacciones entre las dos primeras (Tilly 2000).

Situado históricamente el concepto de repertorio, Tilly (2000) sostiene que en los últimos dos siglos se ha pasado de un tipo de repertorio donde la acción colectiva era local, directa y particularista, a otro en el que la acción colectiva es cosmopolita, modular y autónoma. Así, las modificaciones en el repertorio de contención indican transformaciones de larga duración, las que sucedieron desde el siglo xviII hasta el siglo xx. En este conjunto de transformaciones es preciso destacar la centralidad que asumió el Estado nación durante el siglo xx. En efecto, el Estado en este período ha ofrecido oportunidades diversas para que la acción colectiva se oriente hacia su órbita (Tilly 2000).

\section{DEMOCRATIZACIÓN: SI LA VINCULACIÓN NO ES NECESARIA ¿CUÁNDO SE DA?}

A diferencia de la perspectiva de los movimientos sociales, para este enfoque no existe una necesaria conexión entre movimientos sociales y procesos políticos de democratización. Más bien, resulta preciso pensar como sugiere Tilly (2010) ¿de qué modo y cuándo promueven los movimientos sociales la democratización? Asimismo, ¿cuál es el impacto de los movimientos sociales en la democratización?

No siendo necesaria la conexión entre movimientos sociales $y$ democratización, $y$ quedando sujeta a procesos históricos específicos, los criterios que plantea Tilly (2010) son los siguientes: 1) aumento del número total de personas que participan de la política pública provocado por los aumentos demográficos, urbanización o las guerras; 2) equiparación de recursos y contactos entre estas personas, por ejemplo, mediante la creación legal de electorados; 3) aislamiento de la política pública de las desigualdades sociales existentes eliminando las barreras motivadas por el género, la raza o el origen étnico; 4) incorporación de redes de confianza interpersonales en la política pública que derivan en eliminar el riesgo en una empresa. Cabe destacar que para Tilly "ninguno de estos factores comporta por sí mismo la democratización, pero todos ellos la fomentan, sobre todo si se dan simultáneamente" $(2010,256)$.

De modo que cada proceso político por separado, así como, el accionar político de los movimientos sociales por sí solo activan procesos de democratización. Más bien, su simultaneidad es la que posibilita la generación de relaciones de mayor horizontalidad en la misma sociedad y también, entre gobernantes y gobernados; además, es la que provoca una reducción de desigualdades previamente existentes a la implementación de esta política pública. Así, para el autor, la aparición de nuevas organizaciones (asociaciones, partidos, sindicatos, mutuales, etc.) que mediante su participación en el marco de políticas públicas generan relaciones más horizontales entre los actores políticos y los ciudadanos en general. Entre los casos paradigmáticos que menciona el autor se destaca el caso de Gran Bretaña, que mediante el accionar de los movimientos sociales se generó la reforma de 1830 y 1832, cuyo modelo de democratización tuvo repercusión a nivel mundial. Por el contrario, se menciona el caso de la India a comienzos de siglo xx donde la polarización entre el movimiento social hindú y el musulmán contribuyó a minar el carácter democrático del régimen nacional.

\section{CONCLUSIONES}

Este trabajo analizó el modo en que dos perspectivas de la acción colectiva abordan la cuestión del Estado en un momento decisivo: el de la crisis del Estado de Bienestar. En este sentido, los diagnósticos y el modo en que conciben el papel del Estado en la sociedad repercuten en los caminos que se formularon para la 
transformación social. A su vez, cabe destacar que en estas concepciones teóricas queda pendiente una reflexión sistemática acerca de la mutua incidencia entre Estado y movimientos sociales en el marco de la acción colectiva. De esto se señalan algunas orientaciones teóricas.

Por su parte, la perspectiva identitaria interpretó que con el desarrollo del Estado democrático y benefactor de Europa continental, se activaron procesos políticos que terminaban tergiversando - burocratización o colonización- desde su misma raíz, las identidades que surgieron al calor de la lucha política en la sociedad civil. Esto explica en parte las razones por las que, desde esta mirada analítica, se ha sobredimensionado el papel de los movimientos sociales en las democracias con el objeto de hacer más igualitaria la sociedad. El accionar de los movimientos termina operando mediante el mecanismo de la "influencia" sobre la arena estatal con el objeto de que las decisiones administrativas se conviertan en "legítimas".

Por otra parte, el enfoque de la movilización de recursos, le otorga centralidad al Estado cuando explica el surgimiento y el desarrollo de la acción colectiva. Por ello, no se concibe de forma negativa el desarrollo del Estado, así como tampoco su influencia ni su penetración en la sociedad. Los procesos de democratización se explican fundamentalmente por la presencia o ausencia de elementos de la sociedad en el Estado. Así, el primer criterio mencionado es el de registrar la cantidad de personas que participan de una política pública. En este enfoque, al analizar procesos de democratización, no termina de quedar nítidamente delimitado cuánto se debe al accionar del Estado y cuánto al de los movimientos sociales.

De acuerdo con esto, las posiciones de los enfoques teóricos se pueden sintetizar en privilegiar la organización política de la sociedad civil en detrimento del Estado y viceversa. Si este análisis resulta válido, es posible considerar que entre ambas concepciones existe un campo que no se ha explorado teóricamente de forma exhaustiva: el de la mutua incidencia entre las iniciativas estatales y la organización política de los actores de la sociedad civil.
Así es posible avanzar en orientaciones teóricas que aborden de modo equilibrado y sistemático las interacciones entre la esfera estatal y la dinámica política de los movimientos sociales en la problemática de la acción colectiva:

1) Entre la idea de "colonización" y la de la centralidad del Estado para explicar la acción colectiva existe un espacio intermedio organizado en torno a cómo la actuación política de los movimientos sociales incide en las orientaciones estatales $y$ viceversa. Esto permitiría pensar la complejidad y los diferentes modos que asumen las interacciones entre el Estado $y$ los movimientos sociales.

2) La institucionalización de los movimientos sociales, en tanto identidad política ha sido explicada en su vinculación con el Estado, ya sea esta una relación de cooptación o de articulación. Así, ha quedado pendiente una reflexión sobre cómo se regenera $y$ fortalece una identidad política surgida al calor de la lucha en la sociedad civil y que se nutre del accionar de estos elementos y también, de las políticas públicas.

En definitiva, una reflexión sistemática que plantee la mutua incidencia entre Estado y movimientos sociales posibilitaría debatir, con otros argumentos, el modo en que las sociedades actuales pueden ser más igualitarias.

\section{BIBLIOGRAFÍA}

LIBROS

Cohen, Jean-Louis y Andrew Arato. 2000. Sociedad civil y teoría política. México: Fondo de Cultura Económica.

Colom, Francisco. 1992. "Prólogo" en $L a$ gestión política. Claus Offe. España: Ministerio de Trabajo y Seguridad Social.

Eley, Geof. 2003. Un mundo que ganar. Historia de la izquierda en Europa (1850-2000). España: Editorial Crítica.

Habermas, Jürgen. 1998. Facticidad y validez. España: Trotta, 
Habermas, Jürgen. 1989. Teoría de la acción comunicativa. Argentina: Taurus.

Kirchheimer, Otto. 1980. "El camino hacia el partido de todo el mundo". En Teoría y sociología crítica de los partidos políticos. Editado por Lenk, Kurt y Franz Neumann. España: Anagrama.

Manin, Bernard. 1998. Principios del gobierno representativo. España: Alianza.

McAdam, Doug. 1999. "Orígenes terminológicos, problemas conceptuales, futuras líneas de investigación”. En Movimientos sociales: perspectivas comparadas. Oportunidades politicas, estructuras de movilización y marcos interpretativos culturales. Editado por McAdam, Doug, John McCarthy y Mayer Zald. España: Istmo.

McCarthy, John. 1999. "Adoptar, adaptar e inventar límites y oportunidades". En Movimientos sociales: perspectivas comparadas. Oportunidades politicas, estructuras de movilización y marcos interpretativos culturales. Editado por Doug McAdam, John McCarthy y Mayer Zald. España: Istmo.

Melucci, Alberto. 1999. Acción colectiva, vida cotidiana y democracia. México: El Colegio de México.

Offe, Claus. 1992. La gestión politica. España: Centro de Publicaciones del Ministerio de Trabajo y Seguridad Social.

Offe, Claus. 1990. Contradicciones en el Estado de Bienestar. España: Alianza.

Olson, Mancur. 1992. La lógica de la acción colectiva. México: Limusa.

Portantiero, Juan Carlos. 1983. Los usos de Gramsci. Argentina: Grijalbo.

Tarrow, Sidney. 2004. El poder en movimiento. Los movimientos sociales, la acción colectiva y la política. España: Alianza.

Tarrow, Sidney. 1999. "Estado y oportunidades: la estructuración política de los movimientos sociales". En Movimientos sociales: perspectivas comparadas. Oportunidades politicas, estructuras de movilización y marcos interpretativos culturales. Editado por McAdam, Doug, John McCarthy y Mayer Zald. España: Istmo.

Tilly, Charles. 2010. Los movimientos sociales, 1768-2008. Desde sus orígenes a Facebook. España: Editorial Crítica.

Touraine, Alain. 1995. La producción de la sociedad. México: Editorial unam.

Zald, Mayer. 1999. "Cultura, ideología y creación de marcos estratégicos". En Movimientos sociales: perspectivas comparadas. Oportunidades politicas, estructuras de movilización y marcos interpretativos culturales. Editado por McAdam, Doug, John McCarthy y Mayer Zald. España: Istmo.

PUBLICACIONES PERIÓDICAS

Pérez, Ledesma. 1994. "Cuando lleguen los días de cólera. Movimientos sociales, teoría e historia”. Zona Abierta 69 : 51-120.

Raschke, Joaquín. 1994. "Sobre el concepto de movimiento social". Revista Zona Abierta 69 : 121-134.

Revilla, Marisa. 1994. "El concepto de movimiento social: acción, identidad y sentido". Zona Abierta 69 : 181-213.

Tarrés, María Luisa. 1992. "Perspectivas analíticas en la sociología de la acción colectiva”. Revista de Estudios Sociológicos X, n. $30: 735-758$.

Tilly, Charles. 2000. "Acción colectiva". Apuntes de investigación 4 , n. 6 : 9-32.

Fecha de ingreso: 03/09/2015

Fecha de aprobación: 15/12/2015 